\title{
Proteomic analysis of differentially expressed whey proteins in Guanzhong goat milk and Holstein cow milk by iTRAQ coupled with liquid chromatography-tandem mass spectrometry
}

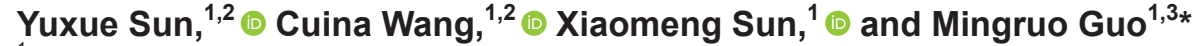 \\ ${ }^{1}$ Key Laboratory of Dairy Science, College of Food Science, Northeast Agricultural University, Harbin, Heilongjiang, 150030, China \\ ${ }^{2}$ Department of Food Science, College of Food Science and Engineering, Jilin University, Changchun, Jilin, 130062, China \\ ${ }^{3}$ Department of Nutrition and Food Sciences, College of Agriculture and Life Sciences, University of Vermont, Burlington 05405
}

\begin{abstract}
Guanzhong goat and Holstein cow milk are the major milks supplied in China. Whey proteins play an important role in immune defense for newborn mammals. This study aimed to analyze the differentially expressed whey proteins of Guanzhong goat milk and Holstein cow milk by using isobaric tags for relative and absolute quantitation (iTRAQ)-based proteomics techniques. A total of 165 whey proteins were quantified, 114 of which differed significantly in abundance in goat and cow milks. According to the "up_keywords," in the online DAVID tool (https://david.ncifcrf.gov/home.jsp), $75 \%$ of these differentially expressed whey proteins were related to the category of "signal." Gene Ontology analyses classified these differentially expressed proteins into biological processes, cellular components, and molecular functions. The most common biological process was response to stress, the most common cellular component was related to extracellular region, and the most prevalent molecular function was binding. Kyoto Encyclopedia of Genes and Genomes pathway analyses showed that these proteins were mainly involved in the complement and coagulation cascade pathways. The results improve our understanding of the different biological properties of whey proteins in goat and cow milks.
\end{abstract}

Key words: whey protein, goat milk, cow milk, proteomics, iTRAQ

\section{INTRODUCTION}

Goat milk and cow milk are the 2 most commonly produced and consumed milks worldwide ( $\mathrm{Li}$ et al., 2019). Whey protein, one of the major milk proteins, has important functions in immune defense of newborn

Received March 19, 2020.

Accepted May 16, 2020.

*Corresponding author: mguo@uvm.edu mammals by homologous transfer (Hurley and Theil, 2011; Pereira, 2014). Whey protein accounts for 18 to $20 \%$ of the total protein content in both goat and cow milks. Whey proteins mainly comprise $\beta-L G, \alpha-L A$, serum albumin, immunoglobulins, lactoferrin, and lactoperoxidase (Madureira et al., 2007; El-Hatmi et al., 2015).

increasing number of whey proteins, especially some low-abundance proteins, have been characterized using proteomic techniques in goat and cow milks. D'Amato et al. (2009) identified 149 proteins from bovine whey using nano-liquid chromatography-tandem mass spectrometry (nLC-MS/MS) combined with combinatorial peptide ligand library technology. Of the proteins identified, 100 were described for the first time in their report. Whey protein composition varies with animal species (Yang et al., 2017a; Lu et al., 2018) and lactation stage (Liao et al., 2011; Yang et al., 2015a; Sun et al., 2020). Lu et al. (2018) compared the whey proteomes of human, cow, goat, and yak milks. Large variations were observed in these 4 types of milk, and complement proteins were highly expressed in human and goat milk. Yang et al. (2017a) identified and quantified 584 whey proteins in human and cow colostrum and mature milk samples, 424 of which differed significantly in abundance between both species and different lactations. Our previous study of whey protein in goat colostrum and mature milk suggested that whey proteins in colostrum were involved in more disease-related pathways, whereas mature milk contained more proteins involved in metabolism-related pathways (Sun et al., 2020). Milk from different breeds of the same species and lactation stage also show different whey protein chemistry (Anagnostopoulos et al., 2016; Tacoma et al., 2016; Li et al., 2018). A few studies have focused on a comparison of whey proteins in goat and cow milks (Yang et al., 2013; Cunsolo et al., 2015; Hernández-Castellano et al., 2016; Sun et al., 2019). However, comparative whey proteomics information for Guanzhong goat milk and Holstein cow milk is very limited. 
Guanzhong goat is a widely distributed dairy goat in China, and its milk is one of the most commonly consumed after Holstein cow milk. The objectives of this study were to characterize differentially expressed whey proteins of Guanzhong goat and Holstein cow milk using an isobaric tags for relative and absolute quantitation (iTRAQ)-based quantitative proteomics approach; the biological functions of these proteins were also examined.

\section{MATERIALS AND METHODS}

\section{Reagents and Equipment}

Protease inhibitor cocktail tablets were purchased from Roche (Mannheim, Germany). Trypsin (sequencing grade) was purchased from Promega Corporation (Madison, WI). Ultra-centrifugal filters (10-kDa cutoff) were purchased from Sartorius (Göttingen, Germany). The C18 (octadecyl) solid-phase extraction disk was purchased from 3M Company (St. Paul, $\mathrm{MN})$. The iTRAQ reagent kit was purchased from $A B$ Sciex Corporation (Foster City, CA). The bicinchoninic acid protein assay kit, dithiothreitol, iodoacetamide, acetonitrile, trifluoroacetate, and formic acid were all purchased from Sigma-Aldrich Corporation (St. Louis, MO). All aqueous solutions were prepared using MilliQ (Millipore, Billerica, MA) water.

\section{Preparation of Whey Protein Samples}

Raw milk samples were collected from 30 Guanzhong goats from Buhui Dairy Co. Ltd. (Changchun, Jilin, China) and 30 Holstein cows from Chunguang Dairy Co. Ltd. (Jilin, Jilin, China). All animals were healthy, and all milk samples were from the first batch milk in the early morning. Whey protein samples from both goat and cow milk were extracted based on a previously reported method (Sun et al., 2020). Briefly, 30 goat milk samples and 30 cow milk samples were mixed separately. Then, whole milk was centrifuged at 8,000 $\times g$ at $4^{\circ} \mathrm{C}$ for 20 min to collect skim milk, and the collected skim milk was centrifuged at 50,000 $\times g$ at $4^{\circ} \mathrm{C}$ for $2 \mathrm{~h}$. Whey proteins were in the resultant liquid phase, and the BCA protein assay kit was used to measure the protein content.

\section{Digestion and ITRAQ Labeling}

Whey proteins were digested according to the method of Sun et al. (2019) with some modifications. Whey protein samples (containing $100 \mu \mathrm{g}$ of whey protein) were reduced with $10 \mathrm{~m} M$ dithiothreitol for $30 \mathrm{~min}$ at $56^{\circ} \mathrm{C}$, and then alkylated with $60 \mathrm{~m} M$ iodoacetamide for $30 \mathrm{~min}$ in the dark at room temperature. The obtained samples were transferred to $10-\mathrm{kDa}$ ultra-centrifugal filters and centrifuged at $14,000 \times g$ for 15 min at room temperature. Then, $300 \mu \mathrm{L}$ of buffer solution $(8 \mathrm{M}$ urea in $100 \mathrm{~m} M$ Tris $/ \mathrm{HCl}, \mathrm{pH} 8.5)$ was added to the ultracentrifugal filters and centrifuged at $14,000 \times g$ for 15 min. This step was repeated twice. Subsequently, 200 $\mu \mathrm{L}$ of dissolution buffer solution (from the iTRAQ kit) was added to the ultrafilters and centrifuged at 14,000 $\times g$ for $15 \mathrm{~min}$. This step was repeated twice. The resulting samples were digested with $1.25 \mu \mathrm{g}$ of trypsin at $37^{\circ} \mathrm{C}$ overnight. The enzymatic hydrolysis was terminated by adding formic acid (10\%), and the resulting peptides were collected.

The collected peptides were then labeled using the 8-plex iTRAQ reagents according to the manufacturer's instructions. Briefly, goat milk peptides were mixed with reagents 115 and 119, and cow milk peptides were mixed with reagents 116 and 121 . The mixed samples were then incubated at room temperature for $2 \mathrm{~h}$. Finally, the labeled peptides samples were desalted. After desalting, the peptide mixtures were vacuum dried and stored at $-20^{\circ} \mathrm{C}$ until analysis.

\section{$n L C-M S / M S$ Analysis}

The Easy nLC 1000 system (Thermo Scientific, Rockford, IL) was used to separate the peptides. Dried peptides were resuspended in mobile phase A $(0.1 \%$ formic acid in water). Then, $4 \mu \mathrm{L}$ of the sample was injected and separated on a C18 analytical column (75 $\mu \mathrm{m} \times 100 \mathrm{~nm}, 3 \mu \mathrm{m})$ with a linear gradient elution of mobile phase B. The mobile phase B was $0.1 \%$ formic acid in $80 \%$ acetonitrile. The flow rate was set at 300 $\mathrm{nL} / \mathrm{min}$.

Q-Exactive-Plus Orbitrap Mass Spectrometry (Thermo Scientific) was used to analyze the separated peptides under the following conditions: the polarity was positive and default charge state was 2 . Full MS was scanned from 350 to 2,000 mass/charge $(\mathrm{m} / z)$ at a resolution of 70,000, and the maximum ion injection time was $50 \mathrm{~ms}$. The resolution for data-dependent MS/MS spectra was set at 17,500 with a fixed first mass of $110 \mathrm{~m} / z$. The normalized collision energy was $32 \mathrm{eV}$ and the dynamic exclusion was $60 \mathrm{~s}$.

\section{Multivariate and Bioinformatical Analysis}

Proteome Discoverer 2.2 Software (Thermo Scientific) was used to analyze the raw data files of MS/ MS by searching against the database of "Ruminantia" (Cunsolo et al., 2015; Anagnostopoulos et al., 2016). 
The peptide and fragment mass tolerance values were $\pm 20 \mathrm{ppm}$ and $\pm 0.1 \mathrm{Da}$, respectively. Trypsin was set to the cleavage enzyme with a maximum missed cleavage of 2. Peptides were identified at a false discovery rate $\leq 0.01$. Differentially expressed whey proteins were selected by an absolute value of fold change in protein abundance $>1.5$. Cluster heatmap analysis was performed using the Heml_1.0 software (CUCKOO Workgroup, Wuhan, China; http://hemi.biocuckoo .org/). The online Database for Annotation, Visualization and Integrated Discovery (DAVID; http:// david.abcc.ncifcrf.gov/home.jsp) was used for analysis of functional categories, Gene Ontology (GO; http:// geneontology.org/) classification, and Kyoto Encyclopedia of Genes and Genomes (KEGG; https://www .genome.jp/kegg/) pathways. Analysis of variance was applied for the differentially expressed proteins with SPSS software (SPSS Inc., Chicago, IL), and $P<0.05$ was considered statistically significant.

\section{RESULTS AND DISCUSSION}

\section{Protein Quantification}

A total of 165 proteins were quantified from goat and cow milk whey fractions. Among these proteins, the well-known components of whey protein, including $\alpha$-LA, $\beta$-LG, serum albumin, and lactotransferrin, were identified. Several caseins, including $\beta-\mathrm{CN}, \alpha_{\mathrm{S} 1^{-}} \mathrm{CN}, \alpha_{\mathrm{S} 2^{-}}$ $\mathrm{CN}$, and $\kappa-\mathrm{CN}$, were also found in the 2 whey fractions. Additionally, immunoglobulin-like domain-containing protein (Uniprot accession number A0A452EH87; https://www.uniprot.org), Tr-type G domain-containing protein (W5PN84), serpin family D member 1 (F6R4P6), lactoperoxidase (G3MXZ0), CSN1S1 (fragment; D3TJW2), enterotoxin-binding glycoprotein PP20K (fragment; Q9TRB9), FAD-binding PCMHtype domain-containing protein (A0A452EZW6), $\alpha$-mannosidase (W5PS45), and major allergen $\beta$-LG (B5B0D4) all existed in high abundance in both whey fractions. These results provided a complete quantitative description of the whey protein fraction in goat and cow milks.

\section{Cluster Analysis}

A cluster heatmap was used to investigate the expression patterns of whey proteins in goat and cow milks, and all 165 proteins were clearly displayed, as shown in Figure 1. Goat and cow milk whey proteins showed different proteomic patterns.

In the present study, the abundance of 126 proteins was upregulated in goat milk, including serum amyloid
A protein (A0A452ECD3, D2U6Q0), polymeric immunoglobulin receptor (A0A452EDG7), fatty acid-binding protein (I1ZAM7), $\beta$-2-microglobulin (A0A452DY37), hemopexin (A0A452DRK5), Ig-like domain-containing protein (W5Q7I2, A0A452EH87, A0A452FF95, A0A452DZD6, A0A452E053), and several uncharacterized immunoglobulin domain proteins (A0A452FQB9, A0A452FQC0, A0A452E2P1, A0A452F449, W5PGE9, A0A452F074, A0A452F0Q0). Different from those of goat milk, cow milk showed 35 upregulated proteins, including xanthine dehydrogenase/oxidase (A0A3Q1LW91), glycosylation-dependent cell adhesion molecule 1 (L8I6N0), IGL@ protein (A5PK49), $\alpha-1$-acid glycoprotein precursor (Q3SZR3), leucine rich Q-2-glycoprotein 1 (F6RMV5), heart fatty acid-binding protein (C0LSL0), serpin A3-1 (A0A452DJK6), major allergen $\beta$-LG (B5B0D4), among others. A previous study reported that whey protein of goat and cow milk yielded different proteomic clustering patterns, and significant differences were observed in abundances of serum amyloid A protein and polymeric immunoglobulin receptor in these 2 milks (Yang et al., 2013).

\section{Differentially Expressed Whey Proteins in Goat and Cow Milk}

Table 1 shows the 114 differentially expressed whey proteins in goat and cow milk (absolute fold change $>1.5, P<0.05)$. Eighty-nine proteins were significantly upregulated in goat milk and 25 proteins were more abundant in cow milk than in goat milk. Among these differentially expressed proteins, $\beta$-caseins (fragment; Q5YD57, Q155X5) were highly abundant in goat milk: Q5YD57 and Q155X5 in goat milk were 18.12 and 13.01 times those of cow milk, respectively. For cow milk, the protein with the highest fold difference was $\beta$-casein (fragment; A9YY83), which was 25-fold higher than that of goat milk. $\alpha_{\mathrm{S} 2}$-Casein (A0A344X7B8) and $\alpha_{\mathrm{S} 1}$-casein (fragment; L8I5S0) ranked second with a fold change of approximately 14.29 (cow:goat).

According to the "Up_Keywords" from the online DAVID tool (https://david.ncifcrf.gov/home.jsp), about $75 \%$ of these differentially expressed whey proteins were signal-related proteins. Secreted and disulfide bond accounted for 65 and $55 \%$ of the proteins, respectively. About $45 \%$ of these proteins were associated with posttranslationally modified glycoproteins. Glycoproteins may protect infants against pathogen infection and can affect inflammation of the intestinal mucosa (Liu and Newburg, 2013). These differentially expressed proteins related to glycoproteins may play a role in protecting infants from disease differently between goat milk and cow milk. Yang et al. (2017b) 
studied the $\mathrm{N}$-glycoproteome profile of whey from dairy animals, and found that goat milk whey shared only 32 glycosylated proteins $(44.4 \%)$ with cow milk whey.

\section{GO Analysis}

All differentially expressed whey proteins were subjected to GO analysis and categorized into biological processes, cellular components, and molecular functions based on their GO annotations (Figure 2). Results indicated that these proteins mainly belonged to the biological process "response to stress," the cellular component "extracellular region," and the molecular function "binding." As shown in Figure 2a, most differentially expressed proteins $(35 \%)$ were involved in the biological process of response to stress, followed by

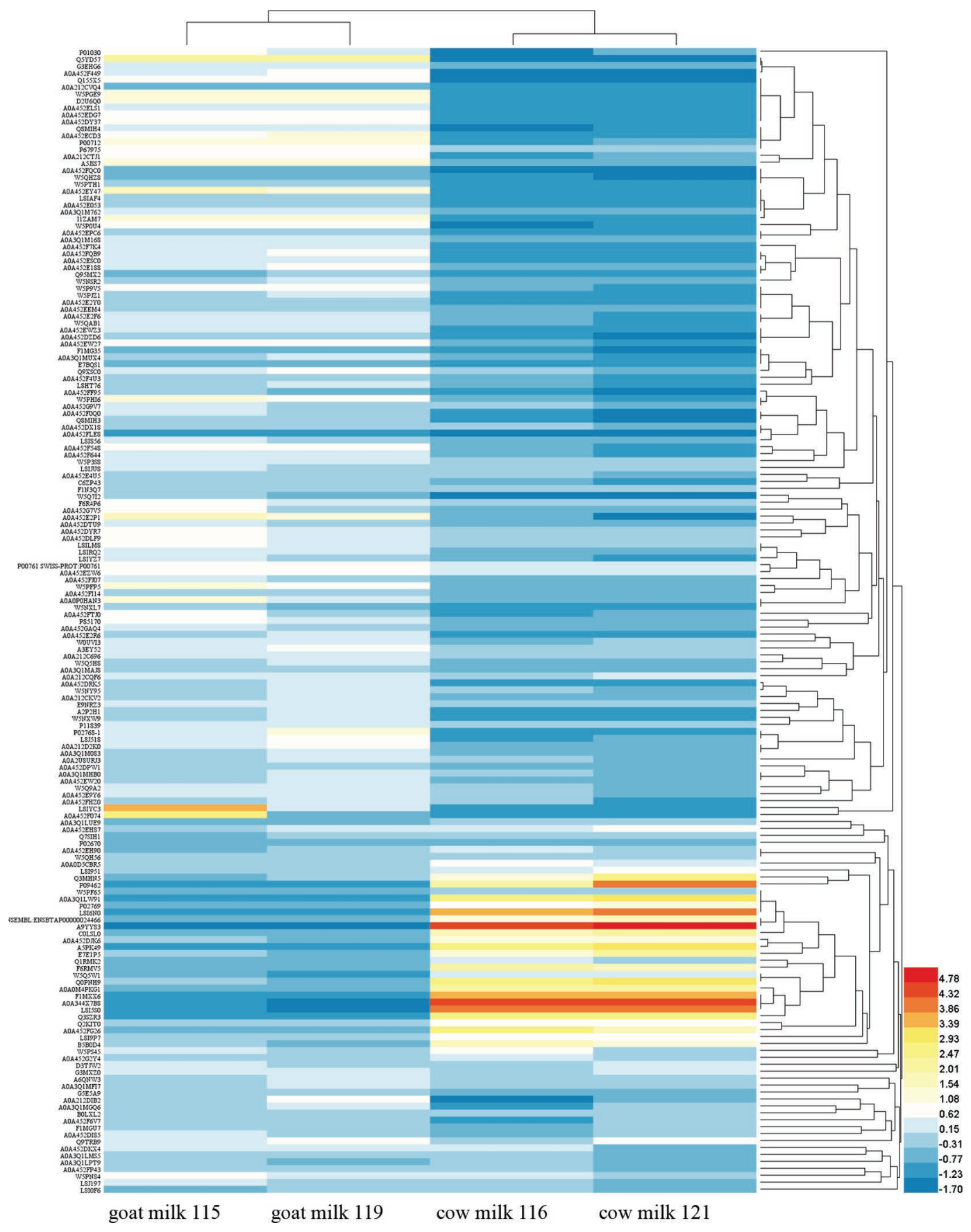

Figure 1. Cluster heatmap of the quantified whey proteins in goat and cow milks labeled with iTRAQ regents $115,119,116$, and 121. 
Table 1. Differentially expressed whey proteins in goat and cow milk

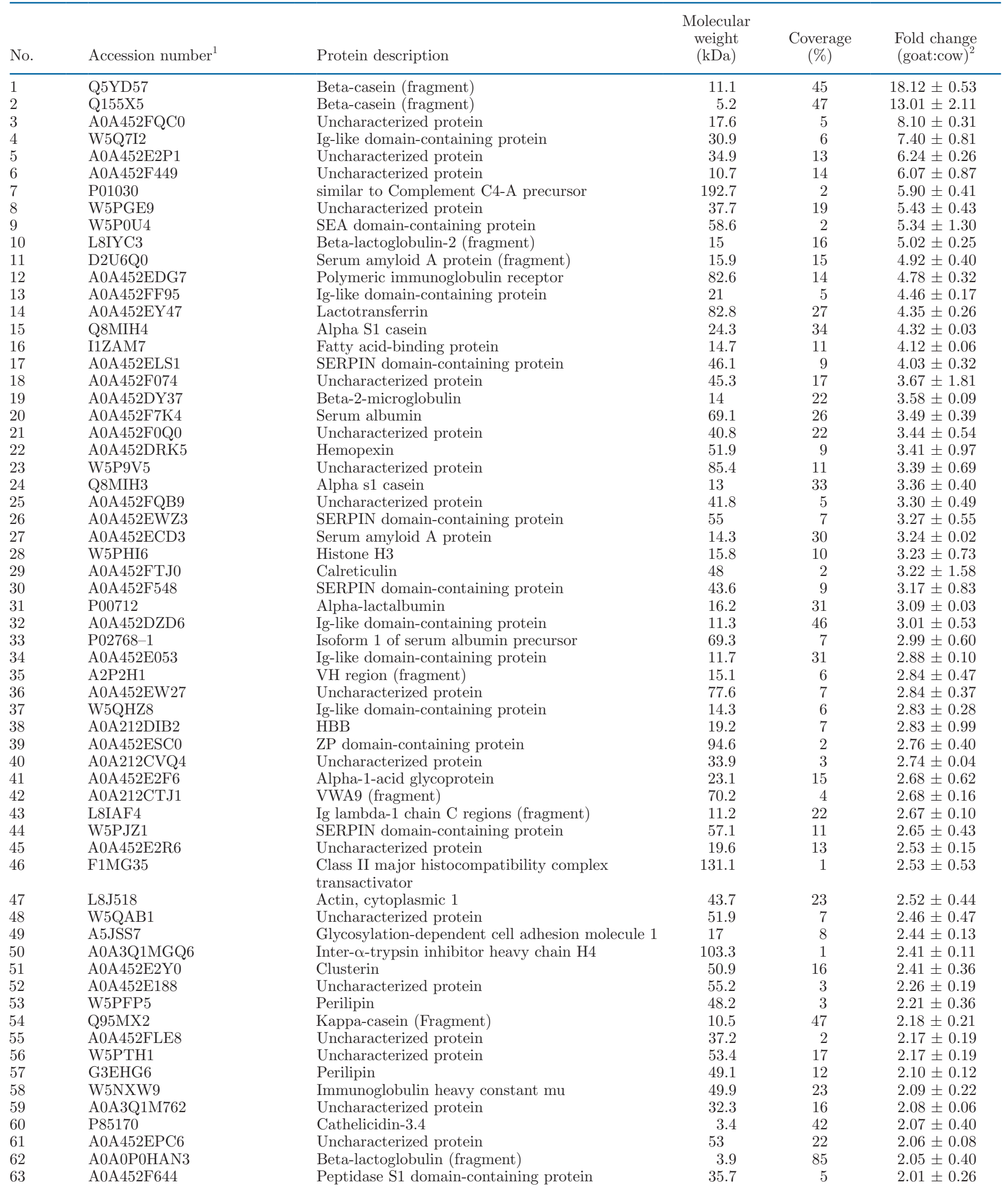


Table 1 (Continued). Differentially expressed whey proteins in goat and cow milk

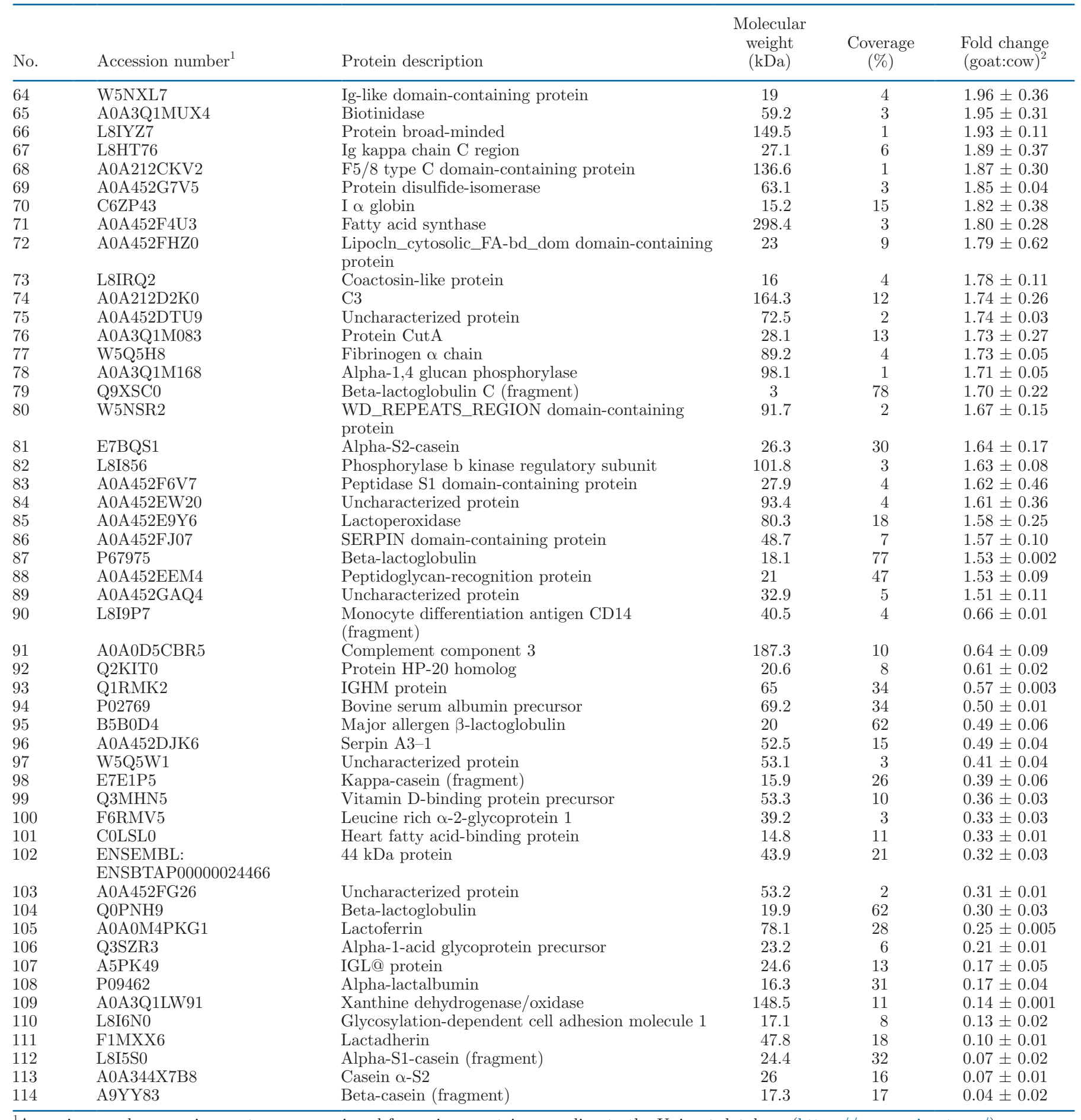

${ }^{1}$ Accession number $=$ unique entry name assigned for a given protein according to the Uniprot database (https://www.uniprot.org/).

${ }^{2}$ Fold change (goat:cow) $=$ ratio of protein abundance of goat milk to that of cow milk; means \pm SD.

defense response, which enriched $20 \%$ proteins. Inflammatory response and transport ranked third at $15 \%$ and acute phase response had $10 \%$ protein involvement. Whey proteins play important roles in immune defense
(Hurley and Theil, 2011; Beck et al., 2015; Sun et al., 2020). The results of the present study suggested that goat milk whey proteins differed in immune defenserelated functions such as stress, defense, inflammation, 
and acute phase compared with cow milk. In a previous study, defense response and immune response were the main biological processes associated with milk serum proteins; the immune proteins of cow milk were similar to those of yak milk but different from those of goat and human milk (Lu et al., 2018).

The most common cellular component was extracellular region, accounting for $65 \%$ of differentially expressed whey proteins (Figure 2b). The second category was extracellular exosome $(55 \%)$, and third was extracellular space (45\%). In previous qualitative analyses on whey proteins of goat and cow milk, the categories of extracellular region, extracellular exosome, and extracellular space were all in the top 5 in both goat and cow milks (Sun et al., 2019). Yang et al. (2017a) reported that extracellular region was the most common cellular component for differentially expressed whey proteins in human and cow milks.

Regarding classification based on molecular function (Figure 2c), binding accounted for $50 \%$ of proteins and was the largest molecular functional category. Ion binding was the second largest category involving 35\% of proteins. Small molecule binding and anion binding followed at $25 \%$. In addition to binding functions mentioned above, these differentially expressed whey proteins showed high affinity with other nutrients, including vitamin, lipid, fatty acid, steroid, and cofactor binding. Similar results were reported in whey proteins of human, yak, buffalo, and camel milks (Yang et al., 2013, 2017a; Lu et al., 2018). Binding was also the most prevalent molecular function in milk fat globule membrane proteins of milks of many species, such as human, goat, cow, and horse (Yang et al., 2015b).

\section{KEGG Pathway Analysis}

The differentially expressed whey proteins were further evaluated using KEGG pathway analysis. Consistent with the results of GO analysis, these proteins principally participated in the immune-related complement and coagulation cascade pathways $(P<0.05)$.

The complement and coagulation cascade pathways are closely related to the immune system and involve many whey proteins (Moreno-Indias et al., 2012; Yang et al., 2013, 2015b, 2017a). The complement system, as a part of the innate immune system, plays an essential role in maintaining the physiological balance of the body. Coagulation cooperates with innate immunity to help the host defend against external invasion (Keragala et al., 2018). Three differentially expressed proteins (P01030, W5Q5H8, and W5PJZ1) in the current study participated in the complement and coagulation cascade pathways. These related proteins are located a

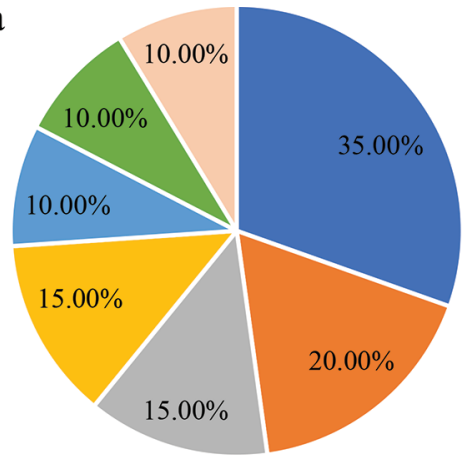

b

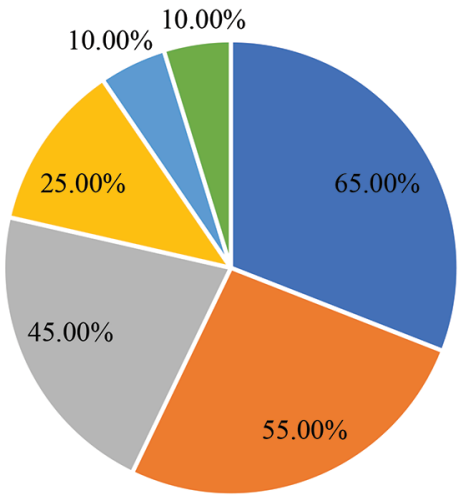

c

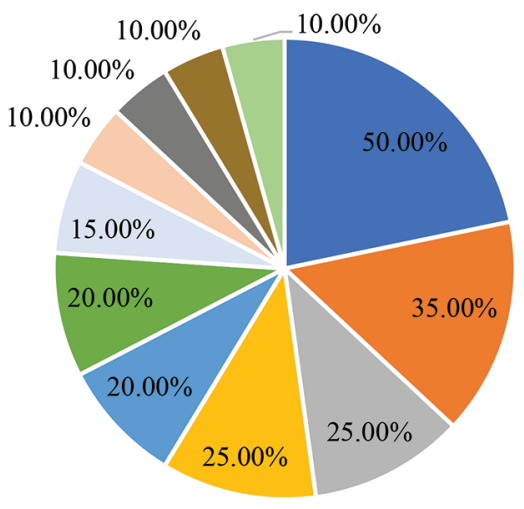

- response to stress

- defense response

- inflammatory response

- transport

- acute-phase response

- hydrogen peroxide catabolic process

cellular oxidant

detoxification

- extracellular region

- extracellular exosome

- extracellular space

- blood microparticle

- fibrinogen complex

- endoplasmic reticulum-Golgi intermediate compartment
- binding

- ion binding

- small molecule binding

- anion binding

- vitamin binding

- lipid binding cofactor binding

- fatty acid binding

- steroid binding

- alcohol binding

- antioxidant activity
Figure 2. Gene Ontology (GO; http://geneontology.org/) classification of differentially expressed whey proteins in goat and cow milks based on biological process (a), cellular component (b), and molecular function (c).

at different positions in these pathways and may affect downstream biological effects by regulating upstream or downstream molecules. For example, in the common pathway of classical and lectin pathways under the complement cascade, differentially expressed proteins similar to complement C4-A precursor (P01030) can participate in the process of cleaving $\mathrm{C} 2$ and $\mathrm{C} 4$ into C4b2a (a C3 convertase), which may alter expression 
of downstream C3b. An important fragment generated during complement activation, and the central link connecting the 3 complement activation pathways, C3b has functions of opsonization and phagocytosis (Dobreva and Stanilova, 2007; Premanandan et al., 2009). The mechanism by which these differentially expressed whey proteins function remains unclear and needs further investigation.

\section{CONCLUSIONS}

A total of 165 proteins were identified and quantified in whey fractions of Guanzhong goat and Holstein cow milks. The expression abundance of 114 proteins in the 2 types of milk differed significantly (absolute fold change $>1.5$ ). Goat milk had more upregulated proteins than cow milk. Functions associated with immunity were abundant in these differentially expressed proteins. These data could improve our understanding of differences in whey proteins in Guanzhong goat milk and Holstein cow milk.

\section{ACKNOWLEDGMENTS}

This study was funded by a special grant of Northeast Agricultural University, Harbin, Heilongjiang, China. Yuxue Sun carried out the experiments, statistical analysis, and drafted the manuscript; Cuina Wang and Xiaomeng Sun participated in certain experiments; Mingruo Guo oversaw the project and revised the manuscript. The authors have stated no conflicts of interest.

\section{REFERENCES}

Anagnostopoulos, A. K., A. I. Katsafadou, V. Pierros, E. Kontopodis, G. C. Fthenakis, G. Arsenos, S. C. Karkabounas, A. Tzora, I. Skoufos, and G. T. Tsangaris. 2016. Milk of Greek sheep and goat breeds; characterization by means of proteomics. J. Proteomics 147:76-84. https://doi.org/10.1016/j.jprot.2016.04.008.

Beck, K. L., D. Weber, B. S. Phinney, J. T. Smilowitz, K. Hinde, B. Lonnerdal, I. Korf, and D. G. Lemay. 2015. Comparative proteomics of human and macaque milk reveals species-specific nutrition during postnatal development. J. Proteome Res. 14:21432157. https://doi.org/10.1021/pr501243m.

Cunsolo, V., E. Fasoli, R. Saletti, V. Muccilli, S. Gallina, P. G. Righetti, and S. Foti. 2015. Zeus, Aesculapius, Amalthea and the proteome of goat milk. J. Proteomics 128:69-82. https://doi.org/10 .1016/j.jprot.2015.07.009.

D'Amato, A., A. Bachi, E. Fasoli, E. Boschetti, G. Peltre, H. Senechal, and P. G. Righetti. 2009. In-depth exploration of cow's whey proteome via combinatorial peptide ligand libraries. J. Proteome Res. 8:3925-3936. https://doi.org/10.1021/pr900221x.

Dobreva, Z. G., and S. A. Stanilova. 2007. The immunomodulatory activity of $\mathrm{C} 3$ binding glycoprotein (C3bgp) is mediated by the complement receptor type III and mitogen-activated protein kinase signal transduction pathways. Immunopharmacol. Immunotoxicol. 29:549-562. https://doi.org/10.1080/08923970701691017.
El-Hatmi, H., Z. Jrad, I. Salhi, A. Aguibi, A. Nadri, and T. Khorchani. 2015. Comparison of composition and whey protein fractions of human, camel, donkey, goat and cow milk. Mljekarstvo 65:159167. https://doi.org/10.15567/mljekarstvo.2015.0302.

Hernández-Castellano, L. E., A. M. Almeida, J. Renaut, A. Arguello, and N. Castro. 2016. A proteomics study of colostrum and milk from the two major small ruminant dairy breeds from the Canary Islands: A bovine milk comparison perspective. J. Dairy Res. 83:366-374. https://doi.org/10.1017/S0022029916000273.

Hurley, W. L., and P. K. Theil. 2011. Perspectives on immunoglobulins in colostrum and milk. Nutrients 3:442-474. https://doi.org/ 10.3390/nu3040442.

Keragala, C. B., D. F. Draxler, Z. K. McQuilten, and R. L. Medcalf. 2018. Haemostasis and innate immunity - A complementary relationship: A review of the intricate relationship between coagulation and complement pathways. Br. J. Haematol. 180:782-798. https://doi.org/10.1111/bjh.15062.

Li, S., L. Li, Q. K. Zeng, J. X. Liu, Y. X. Yang, and D. X. Ren. 2018. Quantitative differences in whey proteins among Murrah, Nili-Ravi and Mediterranean buffaloes using a TMT proteomic approach. Food Chem. 269:228-235. https://doi.org/10.1016/j .foodchem.2018.06.122.

Li, W., M. H. Li, X. Y. Cao, M. Yang, H. J. Han, F. H. Kong, and X. Q. Yue. 2019. Quantitative proteomic analysis of milk fat globule membrane (MFGM) proteins from donkey colostrum and mature milk. Food Funct. 10:4256-4268. https://doi.org/10.1039/ C9FO00386J.

Liao, Y., R. Alvarado, B. Phinney, and B. Lonnerdal. 2011. Proteomic characterization of human milk whey proteins during a twelvemonth lactation period. J. Proteome Res. 10:1746-1754. https:// doi.org/10.1021/pr101028k.

Liu, B., and D. S. Newburg. 2013. Human milk glycoproteins protect infants against human pathogens. Breastfeed. Med. 8:354-362. https://doi.org/10.1089/bfm.2013.0016.

Lu, J., S. W. Zhang, L. Liu, X. Y. Pang, C. L. Ma, S. L. Jiang, and J. P. Lv. 2018. Comparative proteomics analysis of human and ruminant milk serum reveals variation in protection and nutrition. Food Chem. 261:274-282. https://doi.org/10.1016/j.foodchem .2018.04.065.

Madureira, A. R., C. I. Pereira, A. M. P. Gomes, M. E. Pintado, and F. X. Malcata. 2007. Bovine whey proteins - Overview on their main biological properties. Food Res. Int. 40:1197-1211. https:// doi.org/10.1016/j.foodres.2007.07.005.

Moreno-Indias, I., A. W. Dodds, A. Arguello, N. Castro, and R. B. Sim. 2012. The complement system of the goat: Haemolytic assays and isolation of major proteins. BMC Vet. Res. 8:91. https://doi .org/10.1186/1746-6148-8-91.

Pereira, P. C. 2014. Milk nutritional composition and its role in human health. Nutrition 30:619-627. https://doi.org/10.1016/j.nut .2013.10.011.

Premanandan, C., C. A. Storozuk, C. D. Clay, M. D. Lairmore, L. S. Schlesinger, and A. J. Phipps. 2009. Complement protein C3 binding to Bacillus anthracis spores enhances phagocytosis by human macrophages. Microb. Pathog. 46:306-314. https://doi.org/ 10.1016/j.micpath.2009.03.004.

Sun, Y., C. N. Wang, X. M. Sun, and M. R. Guo. 2019. Comparative proteomics of whey and milk fat globule membrane proteins of Guanzhong goat and Holstein cow mature milk. J. Food Sci. 84:244-253. https://doi.org/10.1111/1750-3841.14428.

Sun, Y., C. N. Wang, X. M. Sun, and M. R. Guo. 2020. Proteomic analysis of whey proteins in the colostrum and mature milk of Xinong Saanen goats. J. Dairy Sci. 103:1164-1174. https://doi.org/ 10.3168/jds.2019-17159.

Tacoma, R., J. Fields, D. B. Ebenstein, Y. W. Lam, and S. L. Greenwood. 2016. Characterization of the bovine milk proteome in earlylactation Holstein and Jersey breeds of dairy cows. J. Proteomics 130:200-210. https://doi.org/10.1016/j.jprot.2015.09.024.

Yang, M., X. Cao, R. Wu, B. Liu, W. Ye, X. Yue, and J. Wu. 2017a. Comparative proteomic exploration of whey proteins in human and bovine colostrum and mature milk using iTRAQ-coupled LC- 
MS/MS. Int. J. Food Sci. Nutr. 68:671-681. https://doi.org/10 $.1080 / 09637486.2017 .1279129$.

Yang, Y., X. Zhao, S. Yu, and S. Cao. 2015a. Quantitative proteomic analysis of whey proteins in the colostrum and mature milk of yak (Bos grunniens). J. Sci. Food Agric. 95:592-597. https://doi.org/ 10.1002 /jsfa. 6791

Yang, Y., N. Zheng, X. Zhao, Y. Zhang, R. Han, L. Ma, S. Zhao, S. Li, T. Guo, and J. Wang. 2015b. Proteomic characterization and comparison of mammalian milk fat globule proteomes by iTRAQ analysis. J. Proteomics 116:34-43. https://doi.org/10.1016/j.jprot 2014.12.017.

Yang, Y., D. P. Bu, X. W. Zhao, P. Sun, J. Q. Wang, and L. Y. Zhou. 2013. Proteomic analysis of cow, yak, buffalo, goat and camel milk whey proteins: Quantitative differential expression patterns. J. Proteome Res. 12:1660-1667. https://doi.org/10.1021/pr301001m.
Yang, Y., N. Zheng, X. W. Zhao, Y. D. Zhang, R. W. Han, S. G. Zhao, J. H. Yang, S. L. Li, T. J. Guo, C. J. Zang, and J. Q. Wang. 2017b. $\mathrm{N}$-glycosylation proteomic characterization and cross-species comparison of milk whey proteins from dairy animals. Proteomics 17:1600434. https://doi.org/10.1002/pmic.201600434.

\section{ORCIDS}

Yuxue Sun (1) https://orcid.org/0000-0003-0265-2283

Cuina Wang ๑ https://orcid.org/0000-0002-7528-2458

Xiaomeng Sun $\odot$ https://orcid.org/0000-0002-1132-8584 